\title{
A study of volatility by composition, heating, and dilution measurements of secondary organic aerosol from 1,3,5-trimethylbenzene
}

\author{
Kei Sato ${ }^{1}$, Yuji Fujitani ${ }^{1}$, Satoshi Inomata ${ }^{1}$, Yu Morino ${ }^{1}$, Kiyoshi Tanabe ${ }^{1}$, Toshihide Hikida $^{2}$, Akio Shimono ${ }^{2}$, \\ Akinori Takami ${ }^{1}$, Akihiro Fushimi ${ }^{1}$, Yoshinori Kondo ${ }^{1}$, Takashi Imamura ${ }^{1}$, Hiroshi Tanimoto ${ }^{1}$, and Seiji Sugata ${ }^{1}$ \\ ${ }^{1}$ National Institute for Environmental Studies (NIES), Ibaraki 305-8506, Japan \\ ${ }^{2}$ Shoreline Science Research, Inc., Tokyo, 192-0045, Japan
}

Correspondence: Kei Sato (kei@nies.go.jp)

Received: 12 December 2018 - Discussion started: 16 January 2019

Revised: 24 October 2019 - Accepted: 8 November 2019 - Published: 10 December 2019

\begin{abstract}
Studies of the volatility distribution of secondary organic aerosol (SOA) from aromatic compounds are limited compared with SOA from biogenic monoterpenes. In this study, the volatility distribution was investigated by composition, heating, and dilution measurements for SOA formed from the photooxidation of 1,3,5-trimethylbenzene in the presence of $\mathrm{NO}_{x}$. Composition studies revealed that highly oxygenated monomers $\left(\mathrm{C}_{9} \mathrm{H}_{14} \mathrm{O}_{x}, x=4-7\right)$ and dimers $\left(\mathrm{C}_{18} \mathrm{H}_{26} \mathrm{O}_{x}, x=8-12\right)$ are the major products in SOA particles. Highly oxygenated molecules (HOMs) with five or more oxygens were formed during photochemical aging, whereas dimers degraded during photochemical aging. HOMs with five or more oxygens may be produced from the photooxidation of phenol-type gaseous products, whereas dimers in the particle phase may be photolyzed to smaller molecules during photochemical aging. The results of composition, heating, and dilution measurements showed that fresh SOA that formed from 1,3,5-trimethylbenzene (TMB) photooxidation includes low-volatility compounds with $<$ $1 \mu \mathrm{g} \mathrm{m}^{-3}$ saturation concentrations, which are attributed to dimers. Similar results were reported for $\alpha$-pinene SOA in previous studies. Low-volatility compounds with $<1 \mu \mathrm{g} \mathrm{m}^{-3}$ saturation concentrations are not included in the volatility distributions employed in the standard volatility basis-set (VBS) approach. Improvements in the organic aerosol model will be necessary for the study of anthropogenic SOA as well as biogenic SOA.
\end{abstract}

\section{Introduction}

Secondary organic aerosol (SOA) is a major component of atmospheric fine particles (Zhang et al., 2007), affecting climate (IPCC, 2013) and human health (Dockery et al., 1993; Shiraiwa et al., 2017). Aromatic hydrocarbons are major sources of SOA in urban air (Hayes et al., 2015; Wu and Xie, 2018). SOA formed from the photooxidation of aromatic hydrocarbons is predicted to have a $33 \%$ contribution to the global SOA production by atmospheric-model calculations (Kelly et al., 2018).

Volatility basis-set (VBS) models have improved underestimation of atmospheric organic aerosol levels by accounting for the decrease in organic aerosol volatility with photochemical aging (Robinson et al., 2007). Morino et al. (2015) reported that a VBS model still underestimates organic aerosol concentrations in urban environments, although predictions in remote environments show better agreement with observations. The results reported by Morino et al. (2015) suggest that current VBS models, as well as the emission inventory, still include uncertainties. The volatility distribution of SOA, a key property in the prediction of particle levels in VBS models, has been investigated by several experimental techniques. Lane et al. (2008) used laboratory SOA yield data (e.g., Izumi and Fukuyama, 1990; Odum et al., 1997; Ng et al., 2007) to evaluate the volatility distributions for standard VBS models. The yield curve analysis for laboratory data assumes gas-phase single-step oxidation of volatile organic compounds (VOCs) during laboratory experiments and gasparticle equilibrium. If these assumptions are not applicable, 
the volatility distributions obtained from yield curve analysis may not be accurate.

Particle volatility distribution can also be studied by heating measurements (Baltensperger et al., 2005; Kolesar et al., 2015; Docherty et al., 2018). Heating measurements provide volatilities at high temperatures. The enthalpy of vaporization is needed to determine the volatility distribution at ambient temperatures. Furthermore, thermal decomposition may affect the results obtained by this method. Another technique used to study volatility distribution is the dilution method, which has been successfully applied to the volatility studies of diesel exhaust particles (Robinson et al., 2007; Fujitani et al., 2012). This technique is also used for SOA formed from the $\alpha$-pinene ozonolysis (e.g., Grieshop et al., 2007; Saleh et al., 2013), but to the best of our knowledge, SOA from aromatic hydrocarbons has not been investigated by this method. Saleh et al. (2013) reported that the equilibration timescales for dilution of $\alpha$-pinene SOA particles were several tens of minutes. Data from dilution measurements may be affected by long equilibration timescales due to low particle number concentrations and/or low mass accommodation coefficients.

Chemical analysis can also provide the product volatility distribution as well as formation mechanisms of products. Mass spectrometry combined with a soft ionization method, such as electrospray ionization (ESI) and chemical ionization, can identify a wide range of oxygenated organic molecules. These techniques identified small organic acids, highly oxygenated molecules (HOMs), and oligomers present in SOA particles from aromatic hydrocarbons (Kalberer et al., 2004; Fisseha et al., 2004; Sato et al., 2012; Praplan et al., 2014; Molteni et al., 2018). HOMs are formed through auto-oxidation mechanisms, which include the intramolecular hydrogen abstraction of organic peroxy radicals (Zhang et al., 2017), but it is still unclear whether or not the suggested intramolecular reaction occurs for the peroxy radicals from aromatic hydrocarbons. Oligomers may be produced by acid-catalyzed oligomerization (Kalberer et al., 2004) and/or gas-phase bimolecular reactions of peroxy radicals (Molteni et al., 2018). Recent studies on the parameterization of the saturation concentration (Shiraiwa et al., 2014; Li et al., 2016) and the sensitivity of ESI mass spectrometry (Kruve et al., 2013; Heinritzi et al., 2016) are helpful in the evaluation of SOA volatility using mass analysis data.

In this study, the photooxidation of 1,3,5-trimethylbenzene (TMB) in the presence of $\mathrm{NO}_{x}$ was investigated to evaluate the volatility distribution of SOA. Although the volatility distribution of $\alpha$-pinene SOA has been investigated in several laboratories (Sato et al., 2018 and references therein), the number of studies addressing the volatility of SOA from aromatic hydrocarbons is limited. Products formed from the photooxidation of TMB were further exposed to $\mathrm{OH}$ radicals to study the effect of photochemical aging. The volatility distribution of SOA was evaluated by composition, heating, and dilution measurements. This work aims to evaluate the volatility distribution of SOA from a typical anthropogenic
VOC and discuss SOA formation processes for improving organic aerosol modeling.

\section{Experiments}

\subsection{Chamber experiment}

A $6 \mathrm{~m}^{3}$ Teflon-coated stainless-steel chamber (Sato et al., 2007, 2018) was used for all experiments. Figure S1 in the Supplement shows a schematic diagram of the chamber system and analytical instruments. We listed initial concentrations together with SOA mass concentrations and mean sizes observed immediately before the sampling for the composition or dilution study (Table S1 in the Supplement). Prior to each experiment, the chamber was filled with dry purified air $(1 \mathrm{~atm}$, relative humidity $<1 \%)$. The temperature of the chamber was controlled at $298 \pm 1 \mathrm{~K}$. Required amounts of $\mathrm{TMB}, \mathrm{NO}$, and methyl nitrite were added to the purified air in the chamber. A small amount ( $\sim 0.01 \mathrm{ppm})$ of methyl nitrite was added because it was used as an $\mathrm{OH}$ radical source for the initiation of photooxidation. The reaction mixture in the chamber was irradiated by light from 19 xenon lamps $(1 \mathrm{~kW}$ each) through Pyrex filters. In normal photooxidation experiments (i.e., runs other than run 2), composition, heating, and dilution measurements of SOA particles were conducted after $240 \mathrm{~min}$ irradiation. In an aging experiment (run 2), $\sim 1$ ppmv methyl nitrite was added at 239 and 299 min to expose photooxidation products to $\mathrm{OH}$ radicals. The concentrations of TMB, NO, and methylglyoxal (MEGLY) were measured every $6 \mathrm{~min}$ by a Fourier transform infrared (FT-IR) spectrometer (Nexus 670, Thermo Fisher Scientific, USA), with a $221.5 \mathrm{~m}$ optical path. For dilution measurements, 20 ppmv CO was added to the reaction mixture as a dilution marker. The $\mathrm{CO}$ levels before and after dilution were measured using a CO monitor (model 48i-TLE, Thermo Fisher Scientific, USA).

We investigated SOA formation under dry conditions only because the chamber facility was designed for dry use (Akimoto et al., 1979). Present experiments with dry air will simulate a dry urban atmosphere, in which aqueous-phase chemistry during SOA formation will be suppressed (Kamens et al., 2011; Zhou et al., 2011). In the present study, proton transfer reaction mass spectrometer (PTR-MS) and dilution measurements required the SOA mass concentrations to be $>100 \mu \mathrm{g} \mathrm{m}^{-3}$ in order to obtain sufficient signals (Table S1). In order to form the desired amounts of SOA, we set the initial TMB concentrations to ppm levels. We note that a TMB concentration higher than ambient levels may induce $\mathrm{RO}_{2}+\mathrm{RO}_{2}$ reactions in comparison to ambient conditions, although we observed no experimental evidence of the enhancement of these reactions.

SOA mass concentration was measured every 3 min using an aerosol mass spectrometer (AMS) (H-ToF-AMS, Aerodyne Research, USA) (Aiken et al., 2008). The heating 
measurements were started immediately after sampling for the composition or dilution study. A thermal denuder (TD) equipped with a bypass line (Aerodyne Research, USA) (Huffmann et al., 2008; Faulhaber et al., 2009) was combined with the AMS instrument for heating measurements. During each heating measurement cycle, we used the bypass first for 9 min to obtain the reference data and then used the TD for $15 \mathrm{~min}$ to obtain the data for a specific temperature. Particle size distribution was observed every 3 min using a scanning mobility particle sizer (SMPS) (model 3034, TSI, USA). The effective particle density was measured using a combination of a differential mobility analyzer (DMA) (Sibata Scientific Technology, Japan), an aerosol particle mass analyzer (APM) (Model 3600, Kanomax, Japan), and a condensation particle counter (CPC) (Model 3772, TSI, USA). The effective density of SOA was determined to be $1.40 \pm 0.28 \mathrm{~g} \mathrm{~cm}^{-3}$, which is close to the values found in the literature: 1.35$1.40 \mathrm{~g} \mathrm{~cm}^{-3}$ (Alfarra et al., 2006).

\subsection{LC-TOF-MS analysis}

Chemical composition analysis was conducted using positive-mode ESI liquid-chromatography time-of-flight mass spectrometry (LC-TOF-MS) (Agilent Technologies, UK). The mass calibration and lock-mass correction were conducted using G1969-85000 and G1969-85001 tuning mixtures (Agilent Technologies, UK), respectively. A mass resolution of the mass spectrometer (full width at half maximum) was $>20000$. SOA particles were collected on a Fluoropore Teflon filter (Sumitomo Electric Industries, Japan; $47 \mathrm{~mm} \varphi$, pore size: $1 \mu \mathrm{m}$ ) at $16.7 \mathrm{~L} \mathrm{~min}^{-1}$ for $30 \mathrm{~min}$. The filter sampling was performed at irradiation times of 272 and $411 \mathrm{~min}$ in normal photooxidation (run 1) and aging experiments (run 2), respectively. After sampling, the filter sample was sonicated in $5 \mathrm{~mL}$ methanol for 30-38 min. The filter extract was concentrated to near dryness under $\sim 1 \mathrm{~L} \mathrm{~min}^{-1}$ stream of nitrogen. A $1 \mathrm{~mL}$ formic-acid-methanol-water solution $(v / v / v=0.05 / 100 / 99.95)$ was added to the concentrated extract to obtain the analytical sample. A $10 \mu \mathrm{L}$ aliquot of the analytical sample was injected into the LC-TOF-MS instrument and separated with an octadecyl silica gel column (Inertsil ODS-3, GL Science, Japan; $0.5 \mu \mathrm{m} \times 3.0 \mathrm{~mm} \times 150 \mathrm{~mm})$. A formic-acid-water solution $(0.05 \% v / v)$ and methanol were used as mobile phases. The methanol fraction during each analysis was set at $10 \%$ (0 min), $90 \%$ (30 min), $90 \%$ (40 min), $10 \%$ (45 min), and $10 \%$ (60 min). In our previous study (Sato et al., 2007), the recovery of malic acid with a saturation concentration of $157 \mu \mathrm{g} \mathrm{m}^{-3}$ was determined to be $>90 \%$, suggesting that evaporation loss during pre-treatment is negligible for molecules with saturated concentrations of $157 \mu \mathrm{g} \mathrm{m}^{-3}$ or less.

\subsection{PTR-MS measurements}

Gas and particle products were measured using a PTR-MS (PTR-QMS 500, Ionicon Analytik, Austria) (Lindinger et al., 1998) to determine the saturation concentration of each product (Inomata et al., 2014). To measure the products in the gas phase, online measurements were taken from the filtered chamber air at 240 and $359 \mathrm{~min}$ in the normal photooxidation (run 1) and aging experiments (run 2), respectively. Afterwards, particles were collected on another Fluoropore Teflon filter at $16.7 \mathrm{~L} \mathrm{~min}^{-1}$ for $30-50$ min to measure products in the particle phase. The sample filter was placed in a filter holder, which was then heated at $368 \mathrm{~K}$ under a stream of nitrogen. The gases evaporating from the filter were measured using the PTR-MS. The saturation concentration was calculated from the gas-particle ratio determined by the PTR-MS for each mass-to-carbon ratio $(\mathrm{m} / \mathrm{z})$, assuming gas-particle equilibrium. The procedure used for calculating the saturation concentration is described in Sect. S1 in the Supplement.

\subsection{Dilution measurement}

Another $6 \mathrm{~m}^{3}$ fluorinated ethylene propylene (FEP) film bag was used as an external dilution chamber (EDC) in runs 3 , 4,5 , and 6 . The temperature of the laboratory was controlled at $298 \pm 1 \mathrm{~K}$. Prior to each dilution experiment, the EDC was filled with dry purified air (relative humidity $<1 \%$ ). A necessary amount of reaction chamber air was injected into the EDC using a dilution ejector (FPS-4000, Dekati Ltd., Finland) at $\sim 240 \mathrm{~min}$ of irradiation time. The dilution ratio (DR) was set to 20-86. Dry filtered air was used as the carrier of the dilution ejector. The particle size distribution, particle density, and $\mathrm{CO}$ concentration in the EDC were monitored after the SOA dilution. The required duration for gas transfer from the reaction chamber to the EDC was 13 min or less. During gas transfer, $\mathrm{CO}$ might decrease due to either dilution effects and/or to the reaction with $\mathrm{OH}$ radicals. We ignored the reaction of $\mathrm{CO}$ in the EDC because the EDC was not irradiated. However, before gas transfer was complete, a portion of diluted gas remained in the irradiated reaction chamber; the decrease in this portion might lead to an overestimation of the DR. Even though we assume a maximum level of $\mathrm{OH}$ radicals $\left(10^{7}\right.$ molecules $\left.\mathrm{cm}^{-3}\right)$, CO decreases by only $\leq 2 \%$ due to the reaction with $\mathrm{OH}$ radicals for $\leq 13 \mathrm{~min}$. Thus we ignored the overestimation of the DR due to the reaction of $\mathrm{CO}$ with $\mathrm{OH}$ radicals. We conducted dilution experiments under flow conditions using the dilution ejector in run 7 . We confirmed that negligible evaporation occurred immediately after dilution, in accordance with the previous results reported for $\alpha$-pinene SOA (Grieshop et al., 2007). 


\section{Results and discussion}

\subsection{Time series}

Figure 1 shows a time series of (a) TMB and MEGLY concentrations observed by the FT-IR, (b) SOA mass concentrations observed by the AMS, and (c) O/C the ratio observed for SOA by the AMS during normal photooxidation (run 1) and aging experiments (run 2). The MEGLY concentration increased with decreasing the TMB concentration in runs 1 and 2. Methyl nitrite was added at irradiation times of 239 and $299 \mathrm{~min}$ in run 2. The first injection of methyl nitrite was aimed at completing the photooxidation of the remaining TMB, whereas the second injection was aimed at ensuring that the photooxidation of gaseous secondary products is promoted. The total $\mathrm{OH}$ exposures were determined to be $5.0 \times 10^{10}$ and $6.2 \times 10^{10}$ molecule $\mathrm{cm}^{-3} \mathrm{~s}^{-1}$ for the first (239-299 min) and second exposures (299-359 min), respectively. The total $\mathrm{OH}$ exposures were calculated by integrating the $\mathrm{OH}$ concentrations over irradiation time. The $\mathrm{OH}$ concentration at each irradiation time was calculated assuming the steady state between $\mathrm{OH}$ formation from the methyl nitrite photolysis and $\mathrm{OH}$ reactions with TMB, MEGLY, formic acid, and $\mathrm{NO}_{2}$.

$$
\begin{aligned}
{[\mathrm{OH}]_{\mathrm{ss}} } & =k_{1}[\text { methyl nitrite }] /\left(k_{2}[\mathrm{TMB}]+k_{3}[\mathrm{MEGLY}]\right. \\
& \left.+k_{4}[\text { formic acid }]+k_{5}\left[\mathrm{NO}_{2}\right]\right),
\end{aligned}
$$

where we used present FT-IR data for the concentrations and literature values for the rate coefficients. If we assume that the daytime $\mathrm{OH}$ radical concentration is $10^{6}$, the first and second exposures corresponded to 14 and $17 \mathrm{~h}$ photooxidation under ambient conditions. The TMB that remained after the first addition of methyl nitrite was entirely consumed within $1 \mathrm{~h}$. The concentration of MEGLY slightly increased after the first addition of methyl nitrite due to formation from the remaining TMB and then decreased by the photo-degradation of MEGLY. The decreasing rate of MEGLY increased after the second addition of methyl nitrite, suggesting that the concentration of $\mathrm{OH}$ radicals increased due to the second addition of methyl nitrite.

SOA particles became detectable at an irradiation time of 55-58 min in runs 1 and 2. Afterwards, the SOA mass concentration increased with time, reaching to $\sim 189 \mu \mathrm{g} \mathrm{m}^{-3}$ at 239 min of irradiation time for both runs. After the first addition of methyl nitrite in run 2, the mass concentration of SOA increased to $259 \mu \mathrm{g} \mathrm{m}^{-3}$. SOA, forming after the first addition of methyl nitrite, could be formed from the photooxidation of TMB as well as gaseous secondary products. The mass concentration of SOA then decreased with a rate of $(7.1 \pm 0.1) \times 10^{-5} \mathrm{~s}^{-1}$. The geometric mean particle size after $\mathrm{OH}$ exposure was $558 \mathrm{~nm}$, which was larger than for run 1 $(395 \mathrm{~nm})$. The wall loss rates of ammonium sulfate particles with sizes of 279-322 and 372-429 nm were measured using the present reaction chamber to be $(1.4 \pm 0.6) \times 10^{-5}$ and $(6.1 \pm 3.5) \times 10^{-5} \mathrm{~s}^{-1}$, respectively. Particle wall loss may
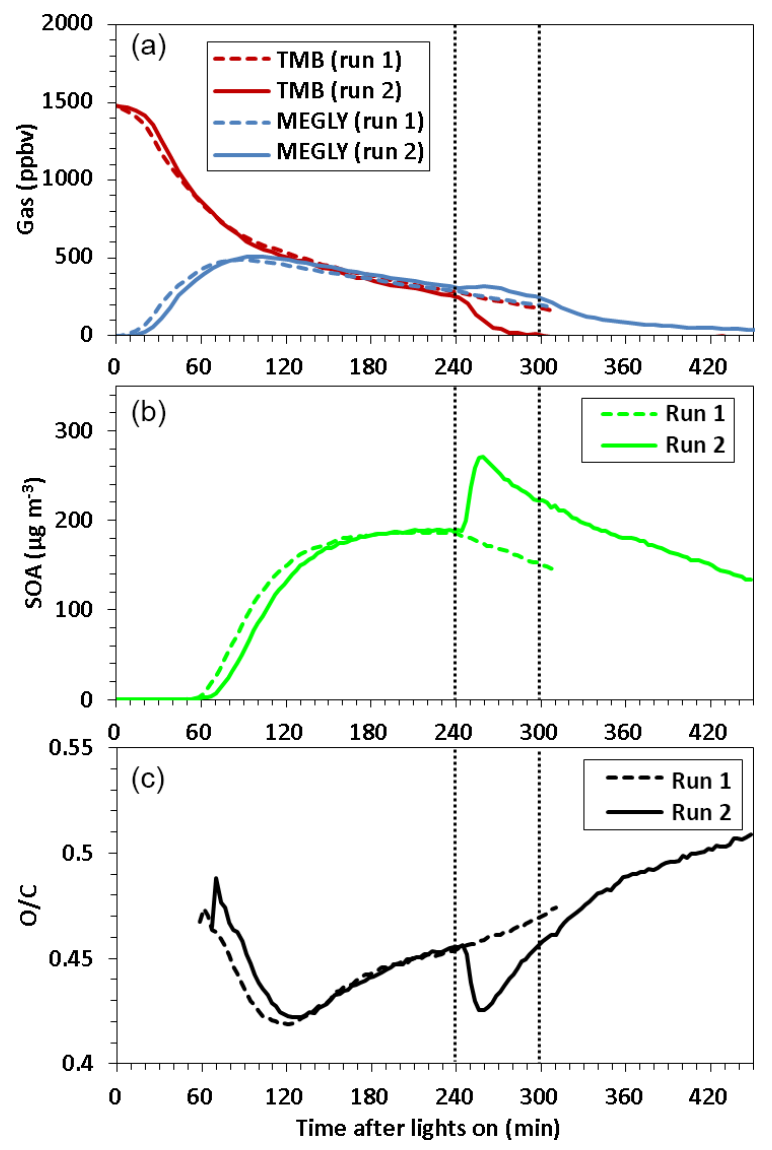

Figure 1. Time series of (a) TMB and methylglyoxal (MEGLY) concentrations observed by FT-IR, (b) SOA mass concentration observed by AMS, and (c) $\mathrm{O} / \mathrm{C}$ ratio observed for organic aerosol by AMS during normal photooxidation (run 1) and aging experiments (run 2). Methyl nitrite was added in run 2 at the irradiation times indicated by vertical dotted straight lines.

explain the observed decrease in SOA mass concentration. No great change in the decreasing rate was observed when methyl nitrite was added for the second time.

In the early stages of SOA formation, the $\mathrm{O} / \mathrm{C}$ ratio decreased with increasing time, probably because new particle formation from HOMs was followed by condensation of less oxygenated compounds from the gas phase. After $\sim 120 \mathrm{~min}$ of irradiation time, the $\mathrm{O} / \mathrm{C}$ ratio increased because of photochemical aging. After the first addition of methyl nitrite in run 2 , the $\mathrm{O} / \mathrm{C}$ ratio decreased, likely because of the formation of fresh SOA from the photooxidation of the remaining TMB or an increase in the mass concentration followed by the condensation of less oxygenated compounds. The O/C ratio reached a minimum at $256 \mathrm{~min}$ and then again increased with time. The $\mathrm{O} / \mathrm{C}$ ratio increased continuously after the second addition of methyl nitrite. Filter sampling of SOA for LC-TOF-MS analysis took place at irradiation times of 272 and $411 \mathrm{~min}$ in runs 1 and 2, respectively. The $\mathrm{O} / \mathrm{C}$ ratio observed at the start time of filter sampling in run 2, 0.50, was 

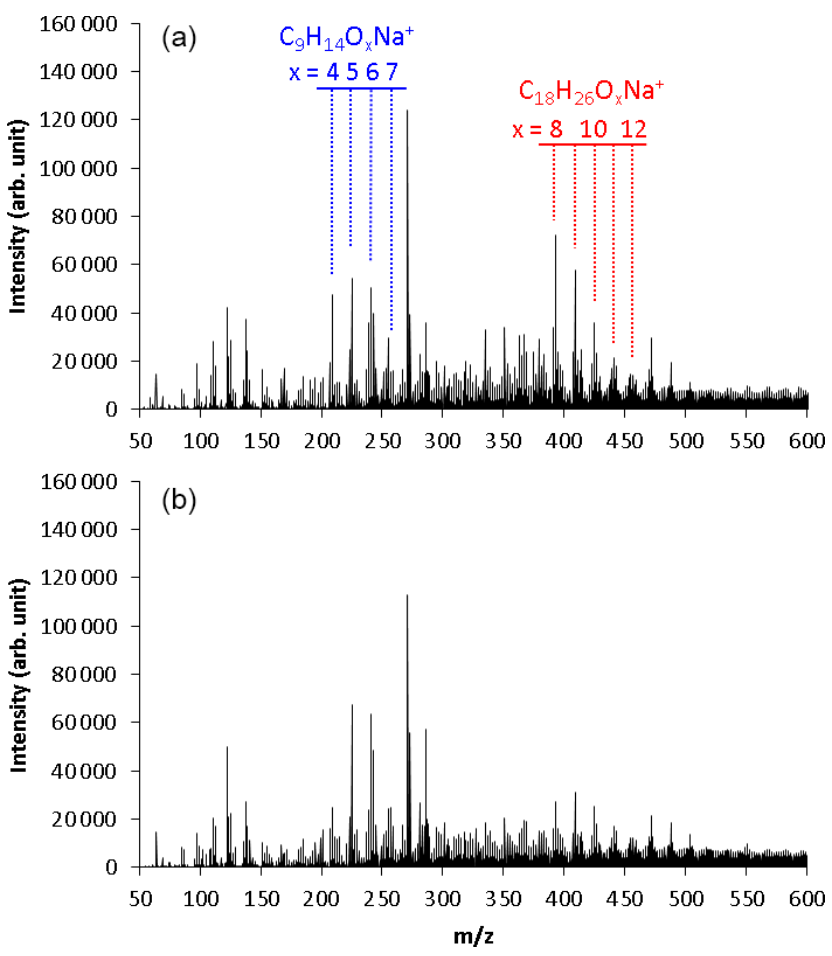

Figure 2. Mass spectra observed using positive-mode electrospray ionization time-of-flight mass spectrometry for TMB SOA samples collected in (a) normal photooxidation (run 1) and (b) aging experiments (run 2). These results were obtained by direct infusion of the SOA samples to the ESI mass spectrometer.

higher than that observed at the start time of filter sampling in run $1,0.46$, indicating that the filter sample collected in the aging experiment must be more highly oxygenated than that collected in the normal photooxidation experiment.

\subsection{LC-TOF-MS analysis}

Figure 2 shows the mass spectra observed using the positivemode ESI mass spectrometer for SOA samples collected in (a) run 1 and (b) run 2 . These results were obtained by direct infusion of SOA samples into the ESI mass spectrometer. Strong signals measured by the positive-mode ESI analysis were identified as sodium-attached product ions. No sodium salt was added to the mobile phase or analytical sample. Species that do not generate stable positive ions through protonation were ionized by clustering with $\mathrm{Na}^{+}$cations that are naturally present in the solvent chemicals and glassware (Kruve et al., 2013; Zhang et al., 2017). The signal intensities of the sodium-attached ions were confirmed to have a linear relationship with the amount of the injected sample.

Two series of mass signals with a regular mass difference of 16 were measured in the regions $m / z, 209-257$ and $m / z$ 393-457. The signals observed in the region $m / z$ 209257 were suggested to be $\mathrm{C}_{9} \mathrm{H}_{14} \mathrm{O}_{x}(x=4-7)$ molecules clustered with $\mathrm{Na}^{+}$. The $\mathrm{C}_{9} \mathrm{H}_{14} \mathrm{O}_{x}$ products are HOMs with the same number of carbons as TMB and two more hydrogens than TMB. The highest peak of $m / z 271$ was also observed in the analysis of blank samples, suggesting that this peak had a contribution from contaminants or solvents. Monomers detected in a previous online study, $\mathrm{C}_{9} \mathrm{H}_{14} \mathrm{O}_{5-11}$ (Molteni et al., 2018), are similar to those detected in our present offline analysis, but monomers detected in the previous study have slightly more oxygens than those detected in this study. A small portion of HOMs may decompose during the present offline analysis.

The signals observed in the region $\mathrm{m} / z$ 393-457 were suggested to be $\mathrm{C}_{18} \mathrm{H}_{26} \mathrm{O}_{x}(x=8-12)$ molecules clustered with $\mathrm{Na}^{+}$. The $\mathrm{C}_{18} \mathrm{H}_{26} \mathrm{O}_{x}$ products have twice as many carbons as TMB. These products are, thus, attributed to dimeric products. Similar products were observed between the samples collected in runs 1 and 2. Largely, monomer signals observed in run 2 were higher than in run 1, whereas dimer signals observed in run 2 were lower than in run 1.

Figure $\mathrm{S} 2$ shows the extracted-ion chromatograms (EICs) observed for (a) $\mathrm{C}_{9} \mathrm{H}_{14} \mathrm{O}_{4} \mathrm{Na}^{+}$, (b) $\mathrm{C}_{9} \mathrm{H}_{14} \mathrm{O}_{5} \mathrm{Na}^{+}$, and (c) $\mathrm{C}_{9} \mathrm{H}_{14} \mathrm{O}_{6} \mathrm{Na}^{+}$by positive-mode LC-TOF-MS. We measured EICs using LC columns because mass signals observed without the column may be interfered from solvent and/or contaminant signals. Contaminant signals were checked from measurements with blank samples, and these contaminant signals were ignored from calculations of product signal intensity. Here, a blank sample was prepared by extracting a new Teflon filter. The method of extraction was similar to that used for the SOA samples. The chromatograms observed for $\mathrm{C}_{9} \mathrm{H}_{14} \mathrm{O}_{4} \mathrm{Na}^{+}, \mathrm{C}_{9} \mathrm{H}_{14} \mathrm{O}_{5} \mathrm{Na}^{+}$, and $\mathrm{C}_{9} \mathrm{H}_{14} \mathrm{O}_{6} \mathrm{Na}^{+}$included at least 9,8 , and 11 chromatographic peaks, respectively, suggesting that each HOM product has a number of structural isomers. The total peak area observed for the $\mathrm{C}_{9} \mathrm{H}_{14} \mathrm{O}_{4}$ products in run 2 was lower than that observed in run 1, whereas the total peak areas observed for $\mathrm{C}_{9} \mathrm{H}_{14} \mathrm{O}_{5}$ and $\mathrm{C}_{9} \mathrm{H}_{14} \mathrm{O}_{6}$ products in run 2 were higher than those observed in run 1 . Note that we collected similar amounts of SOA between runs 1 and 2 (i.e., 122 and $114 \mu \mathrm{g}$ for runs 1 and 2, respectively).

\subsection{Saturation concentration calculations}

Table S2 summarizes the measured mass-to-charge ratio, suggested ion formula, calculated molecular weight, measured total intensity of EIC peaks, calculated $\mathrm{O} / \mathrm{C}$ ratio, and predicted saturation concentrations for products existing in SOA. A common logarithm of the saturation concentration of each product $\left(\log _{10} C^{*}\right)$ was calculated by using Eq. (1), which predicts $\log _{10} C^{*}$ as a function of the number of carbon, nitrogen, and oxygen atoms included in a referred molecule (Li et al., 2016).

$$
\begin{aligned}
\log _{10} C^{*} & =\left(n_{\mathrm{C}}^{0}-n_{\mathrm{C}}\right) b_{\mathrm{C}}-n_{\mathrm{O}} b_{\mathrm{O}} \\
& -2 n_{\mathrm{C}} n_{\mathrm{O}} /\left(n_{\mathrm{C}}+n_{\mathrm{O}}\right) b_{\mathrm{CO}}-n_{\mathrm{N}} b_{\mathrm{N}},
\end{aligned}
$$


where $n_{\mathrm{C}}$ is the number of carbons, $n_{\mathrm{O}}$ is the number of oxygens, $n_{\mathrm{N}}$ is the number of nitrogens, and $n_{\mathrm{C}}^{0}, b_{\mathrm{C}}, b_{\mathrm{O}}$, and $b_{\mathrm{N}}$ are coefficients determined by fitting. Two different sets of coefficients were used in this study. One was a set of coefficients determined by fitting to $\log _{10} C^{*}$ data calculated by a SPARC (SPARC Performs Automated Reasoning in Chemistry) calculator (Hilal et al., 2003) for CHO and CHNO products formed from the photooxidation of TMB. The $n_{\mathrm{C}}^{0}$, $b_{\mathrm{C}}, b_{\mathrm{O}}$, and $b_{\mathrm{N}}$ values determined were $41.53,0.202,0.8805$, -0.05239 , and -1.715 , respectively. The root mean square error (RMSE) of predicted $\log _{10} C^{*}$ was determined to be 1.91, which corresponds to the uncertainty of the predicted $\log _{10} C^{*}$. The other set of parameters is that described by $\mathrm{Li}$ et al. (2016), who fitted the equation to the $\log _{10} C^{*}$ results calculated for over 30000 compounds.

Figure S3 shows a molecular corridor plotted for products from the photooxidation of TMB, where a molecular corridor is a plot of molecular weight as a function of the logarithm of the saturation concentration (Shiraiwa et al., 2014). The saturation concentrations were calculated by a SPARC calculator (Hilal et al., 2003) for products reported by previous experimental studies (Smith et al., 1999; Kalberer et al., 2004; Fisseha et al., 2004; Sato et al., 2012; Praplan et al., 2014) and the Master Chemical Mechanism version 3.3.1 (MCM v3.3.1) (Jenkin et al., 2003). The SPARC calculator predicts vapor pressures accounting for the chemical structure, induction, resonance, and field effects. Table S3 shows simplified molecular-input line entry system (SMILES) code, saturation concentrations determined by the SPARC calculator, and molecular weights for products from the TMB photooxidation. The logarithm of the saturation concentrations calculated for TMB photooxidation products ranged from -7.99 to 9.86 . The saturation concentrations were also determined experimentally from the results of present PTR-MS measurements. Results obtained for $m / z \geq 150$ by PTR-MS were only plotted in the molecular corridor because the signals observed for $m / z<150$ were interfered with by fragmentations from compounds with higher molecular weights. Saturation concentrations calculated by the SPARC calculator showed agreement with those determined by present PTR-MS observations.

\subsection{Volatility distributions based on LC-TOF-MS data}

Figure 3 shows volatility versus carbon number mapping obtained from LC-TOF-MS results for particle-phase products in (a) run 1 and (b) run 2 and the volatility distribution determined for the sum of gas- and particle-phase products in (c) run 1 and (d) run 2. The size of the circle represents the normalized total EIC peak intensity. The volatility versus carbon number mapping shows that low-volatility compounds with $\log _{10} C^{*}<0$ are dimers. The color of the circle represents the $\mathrm{O} / \mathrm{C}$ ratio of each product. The $\mathrm{O} / \mathrm{C}$ ratios of products were determined to be $0.24-0.89$. The saturation concentration was predicted by Eq. (1) and adapted to TMB oxidation products. Compounds of 9-carbon (e.g., $\mathrm{C}_{9} \mathrm{H}_{14} \mathrm{O}_{5}, \mathrm{C}_{9} \mathrm{H}_{14} \mathrm{O}_{6}, \mathrm{C}_{9} \mathrm{H}_{16} \mathrm{O}_{6}$, and $\left.\mathrm{C}_{9} \mathrm{H}_{13} \mathrm{NO}_{8}\right)$ and 18carbon compounds (e.g., $\mathrm{C}_{18} \mathrm{H}_{24} \mathrm{O}_{8}, \mathrm{C}_{18} \mathrm{H}_{26} \mathrm{O}_{8}, \mathrm{C}_{8} \mathrm{H}_{26} \mathrm{O}_{9}$, and $\mathrm{C}_{18} \mathrm{H}_{27} \mathrm{NO}_{12}$ ) are dominant monomer and dimer products, respectively. As discussed previously, signal intensities of dimers decreased during photochemical aging, whereas those of monomers with five or more oxygens increased during photochemical aging. The weighted $\mathrm{O} / \mathrm{C}$ average determined in the aging experiment, 0.57 , was higher than the normal photooxidation experiment, 0.53 , showing a qualitative agreement with the results of the $\mathrm{O} / \mathrm{C}$ ratio measured by the AMS. According to the LC-TOF-MS results, the weighted $\mathrm{O} / \mathrm{C}$ average increased, probably because monomers with five or more oxygens are formed during photochemical aging.

The volatility distributions with 10 bins were calculated for the gas- and particle-phase products, using the results of LC-TOF-MS analysis. The total EIC peak intensities were corrected assuming that the transmission efficiency for timeof-flight mass spectrometry is proportional to $m / z^{1 / 2}$ (Heinritzi et al., 2016). We assumed that the corrected signal intensity is proportional to the mass concentration in the particle phase. We divided the region between $\log _{10} C^{*}=-6.5$ and 3.5 into 10 bins. The mass fraction in the particle phase was calculated for each bin by summing the corrected intensities among the products existing in the referred bin. The mass fraction of the gas phase was calculated assuming gas-particle equilibrium. The compound of $\log _{10} C^{*}=3$ existed predominantly in the gas phase, whereas less volatility compounds existed predominantly in the particle phase under present particle mass conditions. The volatility distributions determined from LC-TOF-MS data were bimodal. Two components of each volatility distribution were attributed to monomer and dimer products. The mass fractions between $\log _{10} C^{*}=0$ and 2 increased during photochemical aging due to the increase in monomers with five or more oxygens, whereas those between $\log _{10} C^{*}=-3$ and -1 decreased during photochemical aging, due to the decrease in dimers. The weighted averages of $\log _{10} C^{*}$ were close between the normal photooxidation (1.15) and aging experiments (1.16). Here, the weighted averages are calculated using the total mass fraction as the weighting factor. We note that the sensitivity of ESI mass spectrometry is compound specific, thus the calculated distribution includes the uncertainties that result from compound-specific sensitivities. In this regard, however sodium adduct formation during ESI can ionize a wide range of oxygenated organic compounds, including carbonyls, peroxides, and alcohols (Kruve et al., 2013; Zhang et al., 2017).

Figure $4 \mathrm{a}-\mathrm{c}$ compare the volatility distributions determined from LC-TOF-MS data employing different methods. Figure 4a shows the volatility distribution determined by predicting saturation concentrations (using Eq. 1 adapted to TMB photooxidation products) and correcting intensities accounting for transmission efficiencies. The volatility dis- 

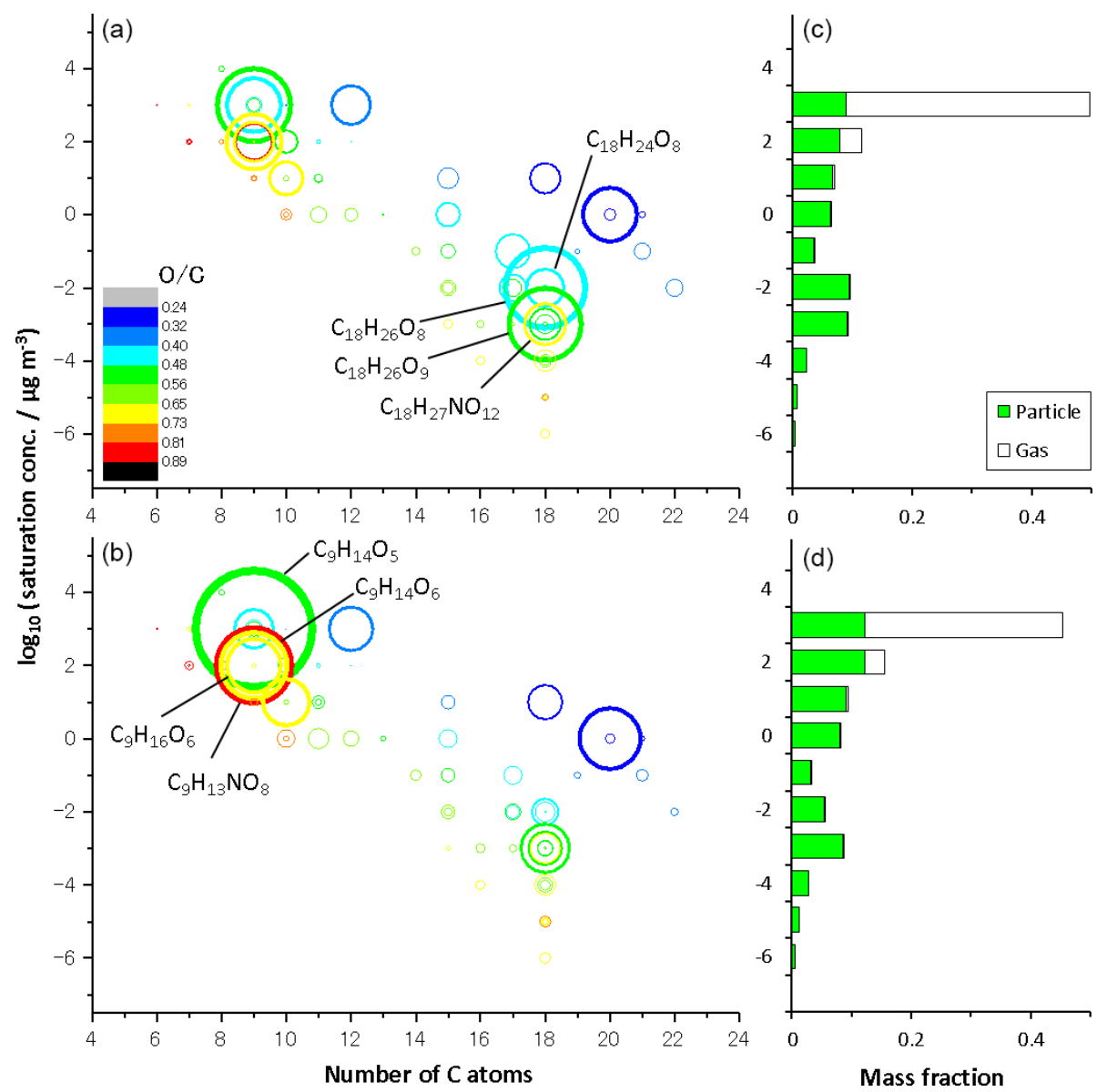

Figure 3. Volatility versus carbon number mapping obtained from LC-TOF-MS results for particulate products in (a) normal photooxidation (run 1) and (b) aging experiments (run 2), and the volatility distribution determined for the sum of gaseous and particulate products in (c) normal photooxidation (run 1) and (d) aging experiments (run 2).

tribution was also calculated without correcting intensities to check the effect of the intensity corrections (Fig. 4b). Similar bimodal volatility distributions were obtained even if the signal intensities were not corrected. The average $\log _{10} C^{*}$ values determined without accounting for intensity corrections for normal photooxidation and aging experiments were 0.80 and 0.83 , which were slightly lower than those determined with intensity corrections. Again, average $\log _{10} C^{*}$ values are weighted by the total mass fraction. The method used for saturation concentration predictions was also checked. Figure $4 \mathrm{c}$ shows the volatility distributions determined employing the unaltered equation proposed by $\mathrm{Li}$ et al. (2016). The average $\log _{10} C^{*}$ values determined for normal photooxidation and aging experiments were 0.34 and 0.39 , respectively, suggesting that the results obtained employing the method of Li et al. were slightly lower than those determined from Eq. (1) adapted to TMB photooxidation products. Even though we take into account uncertainties for the saturation concentrations, all three results determined from LC-TOF-MS data suggest that low-volatility products with $\log _{10} C^{*}<0$ exist in SOA. As shown in Fig. 4f, these low- volatility compounds are not included in the volatility distribution determined by conventional yield curve analysis (Lane et al., 2008).

\subsection{Reaction mechanism}

Figure 5 shows mechanisms suggested for the formation and photochemical aging of abundant products. In this study, we found the $\mathrm{C}_{9} \mathrm{H}_{14} \mathrm{O}_{4-7}$ monomers and the $\mathrm{C}_{18} \mathrm{H}_{26} \mathrm{O}_{8-12}$ dimers to be major products. The photooxidation of TMB is mainly initiated by the addition of $\mathrm{OH}$ radicals to the aromatic ring. The produced adduct reacts with an oxygen molecule to form a peroxy radical, which undergoes a bridging reaction followed by an oxygen molecule addition to form a $\mathrm{C}_{9} \mathrm{H}_{13} \mathrm{O}_{5}$ peroxy radical (TM135BPRO2), according to the MCM mechanism. The TM135BPRO2 peroxy radical can undergo an auto-oxidation process (Wang et al., 2017), namely, intramolecular hydrogen abstraction and the following oxygen addition occur to form a $\mathrm{C}_{9} \mathrm{H}_{13} \mathrm{O}_{7}$ peroxy radical. Molteni et al. (2018) suggested the $\mathrm{RO}_{2}+\mathrm{HO}_{2} \rightarrow \mathrm{ROOH}+$ $\mathrm{O}_{2}$ and $\mathrm{RO}_{2}+\mathrm{RO}_{2} \rightarrow \mathrm{ROOR}+\mathrm{O}_{2}$ reactions for the forma- 


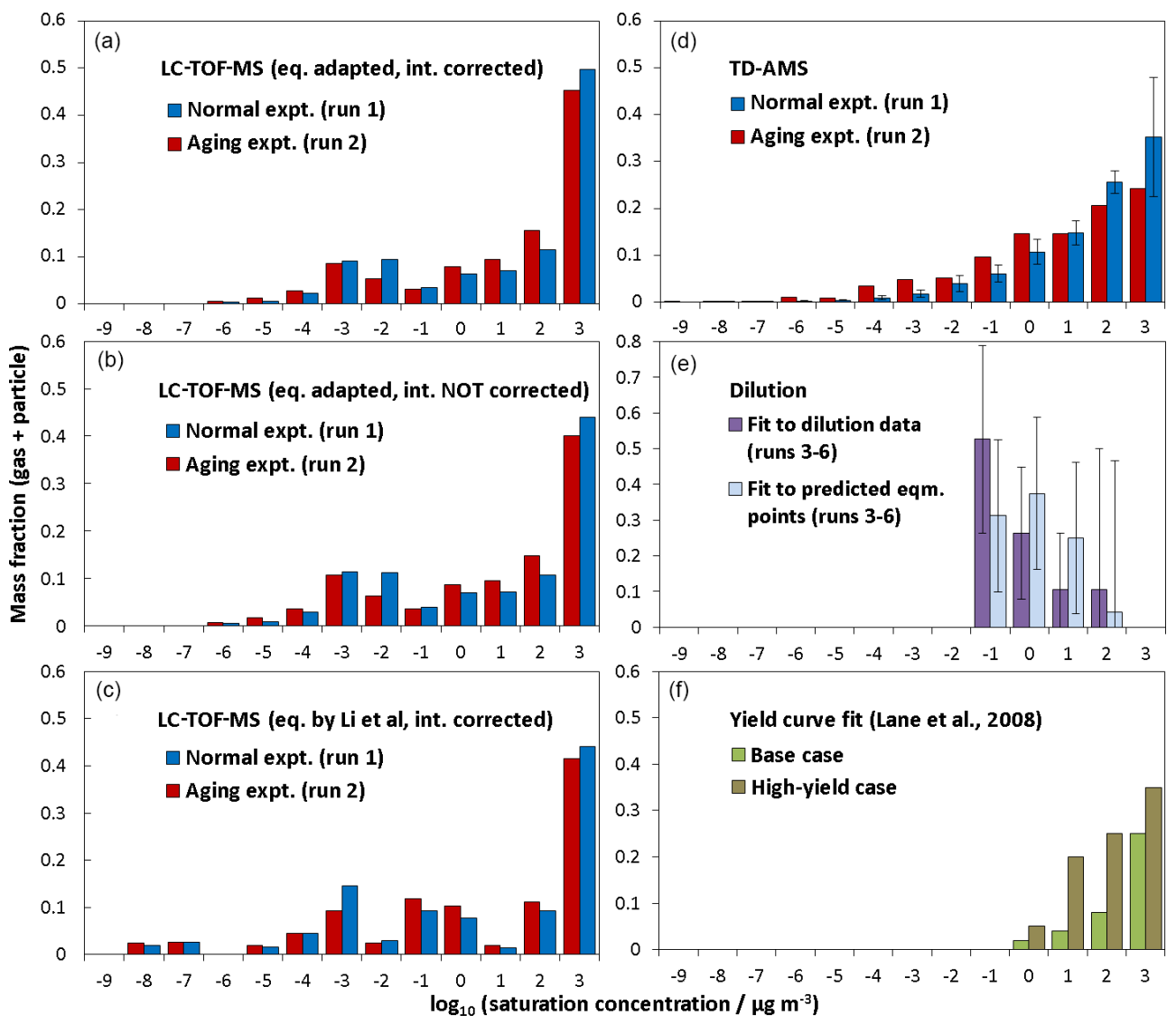

Figure 4. Volatility distributions determined for products from TMB using (a) LC-TOF-MS results, (b) LC-TOF-MS results obtained without intensity correction, (c) LC-TOF-MS results obtained using equation by Li et al. (2016) for saturation concentration calculations, (d) TDAMS results, (e) dilution results, and (f) results of previous yield curve analysis.

tion processes of monomer products (e.g., TM135BPOOH of the MCM mechanism) and dimer products, respectively, where $\mathrm{RO}_{2}$ is a highly oxygenated peroxy radical. Highly oxygenated monomers and dimers may also be formed from ring-opening $\mathrm{RO}_{2}$ radicals (Molteni et al., 2018), which are formed from the following reactions of bicyclic $\mathrm{RO}_{2}$ radicals (i.e., $\mathrm{C}_{9} \mathrm{H}_{13} \mathrm{O}_{5}$ and $\mathrm{C}_{9} \mathrm{H}_{13} \mathrm{O}_{7}$ ).

Since a relatively high concentration (i.e., ppm level) was used for the initial TMB concentration in this study, the autooxidation of $\mathrm{RO}_{2}$ might be suppressed by fast $\mathrm{RO}_{2}+\mathrm{RO}_{2}$ reactions. Currently, accurate rate constant values are not known for intramolecular hydrogen abstraction from $\mathrm{RO}_{2}$ $\left(k_{1}\right)$ and for the $\mathrm{RO}_{2}+\mathrm{RO}_{2}$ reaction $\left(k_{2}\right)$. We conducted the following preliminary calculations: the rate constant for the $\mathrm{CH}_{3} \mathrm{O}_{2}+\mathrm{CH}_{3} \mathrm{O}_{2}$ reaction $\left(4.74 \times 10^{-13} \mathrm{~cm}^{3}\right.$ molecule ${ }^{-1} \mathrm{~s}^{-1}$; DeMore et al., 1997) was employed as $k_{2}$. We assumed the concentration of $\mathrm{RO}_{2}$ during the chamber experiments under ppm level conditions to be $<10^{10}$ molecule $\mathrm{cm}^{-3}$. If this is the case, $k_{2}\left[\mathrm{RO}_{2}\right]$ is determined to be $<4.74 \times 10^{-3} \mathrm{~s}^{-1}$, which is sufficiently lower than the $k_{1}$ value assumed for intramolecular hydrogen abstraction from $\mathrm{RO}_{2}\left(0.1 \mathrm{~s}^{-1}\right.$; Praske et al., 2018). These results suggest that $\mathrm{RO}_{2}$ auto-oxidation will dominate even under ppm level conditions.

The mechanisms suggested by Molteni et al. (2018) can explain the number of hydrogen atoms in $\mathrm{C}_{18} \mathrm{H}_{26} \mathrm{O}_{x}$ dimers because monomer peroxy radicals have the structure $\mathrm{C}_{9} \mathrm{H}_{13} \mathrm{O}_{x}$. For example, the bimolecular reaction between TM135BPRO2 $\left(\mathrm{C}_{9} \mathrm{H}_{13} \mathrm{O}_{5}\right)$ radicals leads to the formation of $\mathrm{C}_{18} \mathrm{H}_{26} \mathrm{O}_{8}$ dimer $+\mathrm{O}_{2}$. The $\mathrm{RO}_{2}+\mathrm{RO}_{2}$ reactions also have another product pathway to form a combination of carbonyl and alcohol monomers (e.g., formation of $\mathrm{TM} 135 \mathrm{BP} 2 \mathrm{OH}+\mathrm{TM} 135 \mathrm{BPOH}$ in the MCM mechanism). The $\mathrm{O} / \mathrm{C}$ ratios of the $\mathrm{C}_{18} \mathrm{H}_{26} \mathrm{O}_{8-12}$ dimers, 0.44-0.67, were similar to those of the $\mathrm{C}_{9} \mathrm{H}_{14} \mathrm{O}_{4-7}$ monomers, 0.44-0.78. The mechanisms suggested by Molteni et al. (2018) are also consistent with the results of the $\mathrm{O} / \mathrm{C}$ ratios; in this mechanism, the $\mathrm{O} / \mathrm{C}$ ratios of monomers and dimers are determined by those of abundant $\mathrm{RO}_{2}$ radicals present during photooxidation.

If we assume ROOR-type structures for dimers, the dimers existing in particle phase could be photolyzed during photochemical aging to form $\mathrm{RO}+\mathrm{RO}$. RO radicals, e.g., TM135BPRO in the MCM mechanism, may decom- 


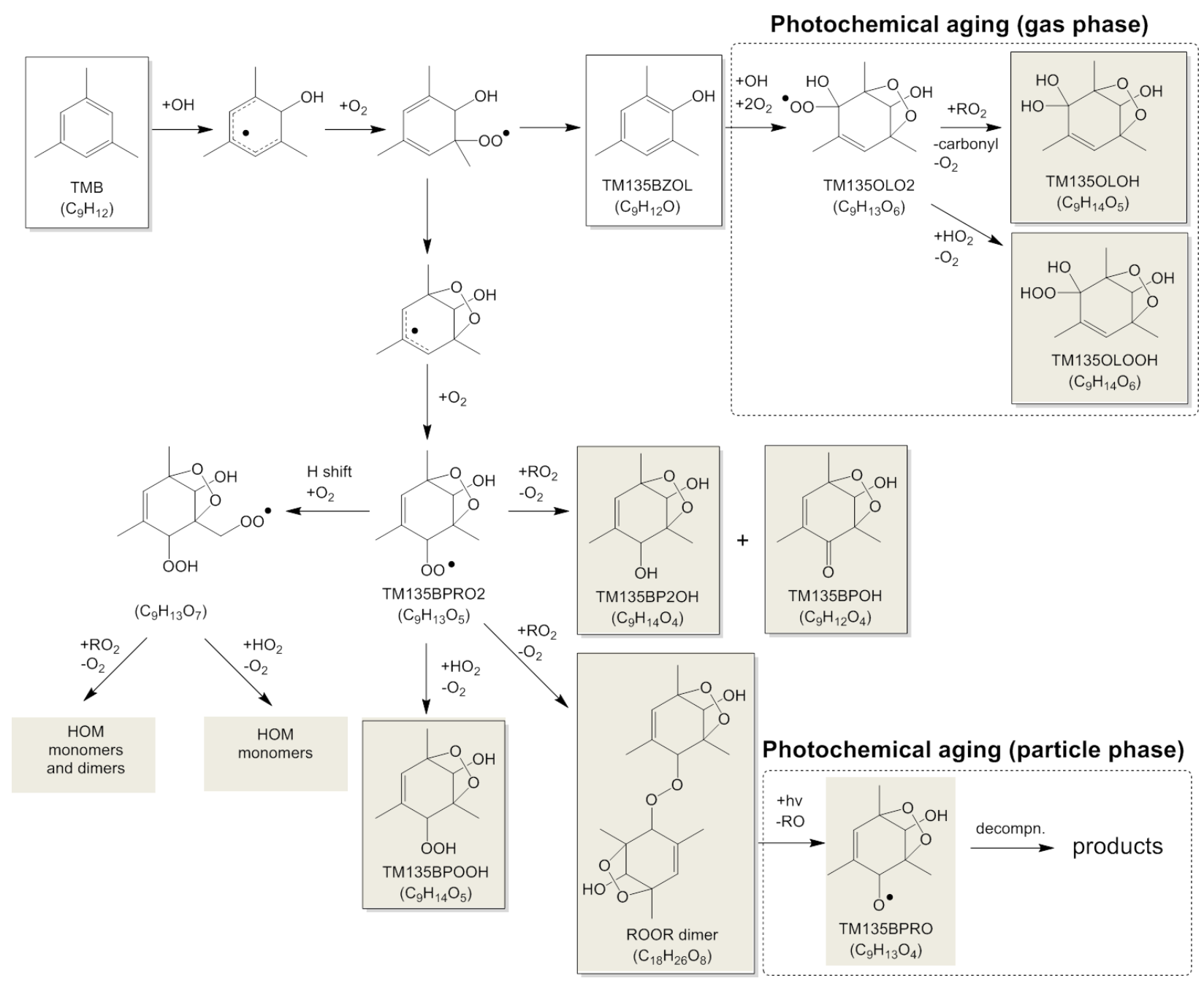

Figure 5. Suggested mechanism for the formation and photochemical aging of abundant products. Shaded products may exist predominantly in the particle phase.

pose to smaller fragments, methylglyoxal, and a C6 counter product. These smaller fragments existing in the particle phase may evaporate because their volatilities are higher than the original ROOR dimers or RO radicals. The volatility distributions determined from LC-TOF-MS data showed that dimers comprise $25 \%-49 \%$ of the total product mass. The gas-phase $\mathrm{RO}_{2}+\mathrm{RO}_{2}$ reactions may not fully explain the mass ratio of dimer products because the rate constant for the $\mathrm{RO}_{2}+\mathrm{RO}_{2} \rightarrow \mathrm{ROOR}+\mathrm{O}_{2}$ reactions, $3.0 \times$ $10^{-14} \mathrm{~cm}^{3}$ molecule ${ }^{-1} \mathrm{~s}^{-1}$ (Atkinson et al., 1989), was lower than that for $\mathrm{RO}_{2}+\mathrm{HO}_{2} \rightarrow \mathrm{ROOH}+\mathrm{O}_{2}$ reactions, $5.6 \times$ $10^{-12} \mathrm{~cm}^{3}$ molecule $\mathrm{s}^{-1}$ (DeMore et al., 1997). These results suggest that other dimer formation processes cannot be excluded. The probable additional formation processes for dimers are acid-catalyzed particle-phase reactions (Kalberer et al., 2004) or gas-phase reactions of organic compounds with Criegee intermediates. Criegee intermediates may be produced during photooxidation because ozone can react with unsaturated photooxidation products (Sato et al., 2004). Present LC-TOF-MS results show that $\mathrm{C}_{9} \mathrm{H}_{14} \mathrm{O}_{5}$ and $\mathrm{C}_{9} \mathrm{H}_{14} \mathrm{O}_{6}$ products are produced during photochemical aging. These five- and six-oxygen monomers are produced by the photooxidation of gaseous phenol-type compounds formed from TMB photooxidation (Nakao et al., 2011). The compound 2-Hydroxy-1,3,5-trimethylbenzene (TM135BZOL of the MCM mechanism) is formed as a primary product of TMB photooxidation. According to the MCM mechanism, this phenol-type product reacts with $\mathrm{OH}$ radicals to form the TM135OLO2 peroxy radical. This peroxy radical reacts with $\mathrm{RO}_{2}$ to form TM135OLOH or reacts with $\mathrm{HO}_{2}$ to form TM135OLOOH, suggesting that the $\mathrm{C}_{9} \mathrm{H}_{14} \mathrm{O}_{5}$ and $\mathrm{C}_{9} \mathrm{H}_{14} \mathrm{O}_{6}$ products are formed from the photooxidation of TM135BZOL during photochemical aging. The peroxy radical, TM135OLO2, may also react with $\mathrm{NO}_{2}$ to produce peroxy nitrate, $\mathrm{C}_{9} \mathrm{H}_{13} \mathrm{NO}_{8}$. 


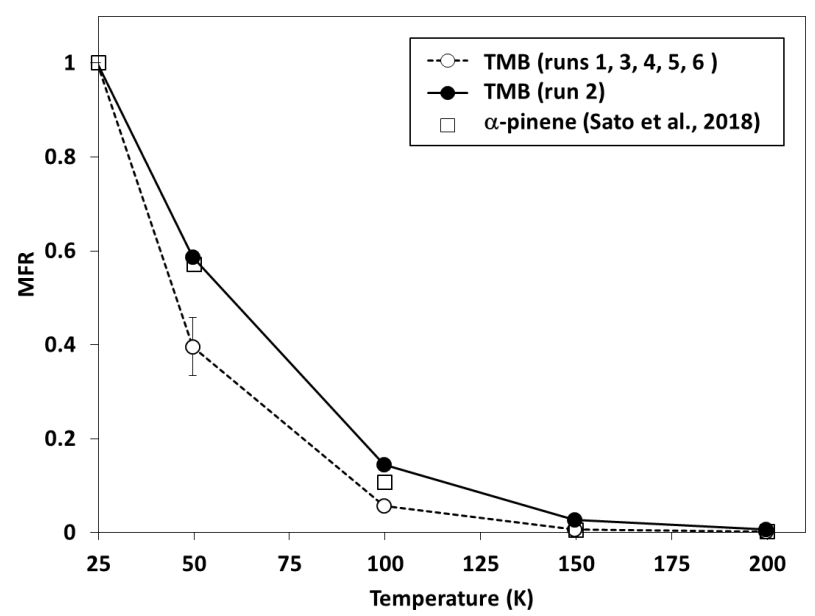

Figure 6. Mass fraction remaining (MFR) for SOA formed from the photooxidation of TMB as a function of thermal denuder temperature (thermogram).

\subsection{TD-AMS measurements}

Figure 6 shows the mass fraction remaining (MFR) observed for SOA as a function of TD temperature (thermogram). Results obtained for SOA in normal photooxidation experiments are averages from runs $1,3,4,5$, and 6 . The error bars quoted for results of the normal photooxidation experiments are standard deviations. The MFR results observed between 50 and $150^{\circ} \mathrm{C}$ in the aging experiment were slightly higher than those from normal photooxidation experiments, but these differences may not be significant because results of the aging experiment were obtained from only one experimental run. The thermogram observed for SOA, formed from $\alpha$-pinene ozonolysis without photochemical aging in our previous study (Sato et al., 2018), was similar to that observed for SOA from TMB in the aging experiment in this study. The transmission efficiency of 50-250 nm sodium chloride particles was reported to be $>80 \%$ in the region $298-498 \mathrm{~K}$ for a TD with the same design as the present TD (Huffmann et al., 2008). We ignored particle wall loss in the TD during the data analysis.

Figure $4 \mathrm{~d}$ shows the volatility distribution determined from the results of the heating measurements. Thermogram data were converted into volatility distributions using an empirical method developed by Faulhaber et al. (2009). Faulhaber et al. (2009) measured the relationship between the saturation concentration and the TD temperature at which MFR becomes 0.5 for several kinds of single-compound particles. We used the results of the calibration curve from Faulhaber et al. (2009) directly, as the TD in our study has the same design as their TD and has a residence time $(\sim 13 \mathrm{~s}$ at $298 \mathrm{~K})$ close to that used for their TD $(\sim 15 \mathrm{~s} 298 \mathrm{~K})$. Furthermore, we confirmed that their calibration curve agreed with our results obtained for pinonic acid particles (Sato et al., 2018). The volatility distributions determined from TD-AMS data

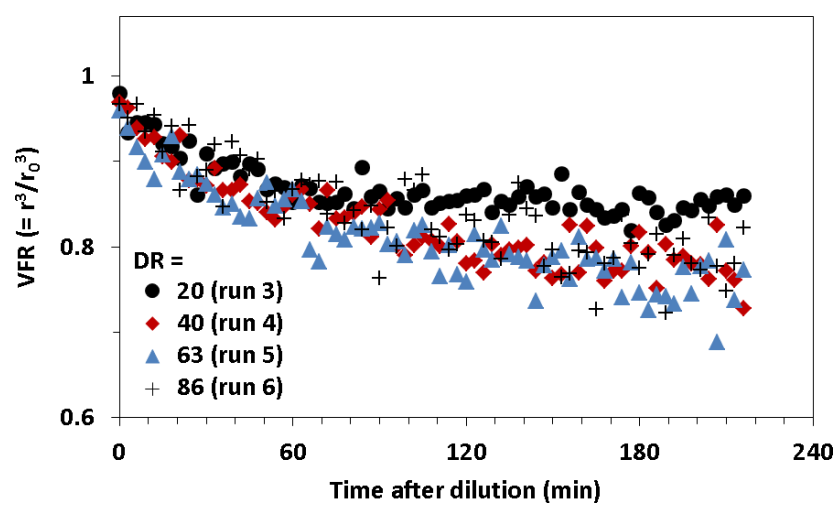

Figure 7. Volume fraction remaining (VFR) for SOA particles formed from the photooxidation of TMB as a function of time after dilution.

included low-volatility products with $\log _{10} C^{*}<0$, showing agreement with results obtained from LC-TOF-MS data. The weighted averages of $\log _{10} C^{*}$ determined from TD-AMS data for normal photooxidation and aging experiments were 1.44 and 0.65 , respectively. The mass fractions determined between $\log _{10} C^{*}=-4$ and 0 for aging experiments were slightly higher than those determined for normal photooxidation experiments, but again these differences may not be significant.

\subsection{Dilution measurements}

Figure 7 shows the volume fraction remaining (VFR) observed for SOA as a function of time after dilution. The number concentration and mean size of SOA particles decreased with increasing time during dilution measurements. We assumed that the decrease in the number concentration resulted from particle wall loss, and the decrease in the mean size resulted from particle evaporation. To remove the influence of wall loss, the VFR was determined by $r^{3} / r_{0}^{3}$, where $r$ is the geometric mean radius of particles and $r_{0}$ is the geometric mean radius immediately before dilution. We observed the time series of the VFR at the DRs of 20, 40, 63, and 86. Although evaporation is assumed to occur instantaneously in gas-particle equilibrium partitioning models, the VFR of SOA particles decreased very slowly. The VFR reached equilibrium more than $2 \mathrm{~h}$ after dilution, and in some cases, it did not reach equilibrium at all within the observation duration.

The equilibration timescale $(\tau)$ for gas-particle equilibrium could be expressed as a function of the particle size, the particle number concentration, and the mass accommodation coefficient (Saleh et al., 2013). Figure S4 shows plots of effective saturation ratios as a function of $t / \tau$. Here, $\tau$ was calculated by Eq. (2).

$$
\begin{aligned}
\tau & =(1+0.3773 K n+1.33 K n(1+K n) / \alpha) / \\
& (2 \pi D(1+K n) d N)
\end{aligned}
$$


In this expression, $K n$ is the Knudsen number, $\alpha$ is the mass accommodation coefficient, $D$ is the gas-phase diffusion coefficient, $d$ is the particle geometric mean diameter, and $N$ is the particle number concentration. The $\alpha$ value was treated as the fitting parameter. An effective saturation ratio $\left(\mathrm{SR}_{\mathrm{eff}}\right)$ in Fig. S4 is defined as the ratio of the total vapor concentration in the gas phase to the vapor concentration at equilibrium, as expressed by Eq. (3).

$\mathrm{SR}_{\mathrm{eff}}=\frac{\sum C_{g, i}}{C_{\mathrm{sat}, \mathrm{eff}}}=\frac{\sum C_{g, i}}{\sum x_{i} \gamma_{i} C_{\mathrm{sat}, i}}$,

where $C_{\text {sat,eff }}$ is the effective saturation concentration, $x_{i}$ is mole fraction, $\gamma_{i}$ is the activity coefficient, and $C_{\mathrm{sat}, i}$ is the saturation concentration of component $i$. The time variation of $\mathrm{SR}_{\mathrm{eff}}$ is approximately a 1st-order variation if the change in the particle mass concentration after dilution is less than several tens of percent, as expressed by Eq. (4).

$\mathrm{SR}_{\mathrm{eff}}=1-e^{-t / \tau}$

Fitting Eq. (4) to experimental results, we determined the equilibration timescales of $\mathrm{DR}=20,40,63$, and 86 to be $68 \pm 17,174 \pm 40,275 \pm 65$, and $399 \pm 94$ min, respectively. The current results of a 68-399 min equilibration timescale was similar to or higher than our previous results reported for $\alpha$-pinene SOA, due to similar or lower number concentrations $\left(32-212 \mathrm{~cm}^{-3}\right)$ during present dilution experiments. We also determined the mass accommodation coefficient from the fitting to be $0.7 \pm 0.3$. The mass accommodation coefficient includes all resistance to gas-particle partitioning other than gas-phase diffusion, for example, surface accommodation and diffusion limitations in the particle phase (Saleh et al., 2013). The existence of low-volatility materials in SOA, kinetic inhibition, or some combined effect may explain an accommodation coefficient of less than unity. The mass accommodation coefficient determined for SOA from TMB was higher than that estimated for $\alpha$-pinene SOA in our previous study $(0.1)$.

The normalized SOA yields determined for the observed dilution data and predicted equilibrium points are plotted as a function of particle concentration (Fig. S5). The normalized yield of the vertical axis is based on the VFR determined from particle size, whereas the particle concentration of the horizontal axis is the actual concentration affected by particle wall loss in the EDC. The particle wall loss rate in the EDC was observed to be $2.5 \times 10^{-5} \mathrm{~s}^{-1}$. We extrapolated observed dilution data to predict normalized yields and particle concentrations at gas-particle equilibria using results obtained by the present equilibration timescale analysis. The observed dilution data and the predicted equilibrium data were fitted by Eq. (2) in Grieshop et al. (2007) to determine the volatility distributions, respectively. We determined the volatility distributions only for $\log _{10} C^{*}=-1,0,1$, and 2 accounting for the mass concentration region examined. The bin of $\log _{10} C^{*}=-1$ needed to have a non-zero mass fraction in order to explain observed dilution data or predicted equilibrium data. Figure 4e shows the volatility distributions determined from the results of dilution measurements. The errors quoted for the volatility distributions were uncertainties in the fitting analysis. The volatility distribution determined from dilution data also shows that low-volatility products with $\log _{10} C^{*}<0$ are present, contradicting the volatility distributions predicted from yield curve analysis.

\subsection{Implications of data from different methods}

There are not only statistical uncertainties for volatility distributions obtained from each technique but also systematic uncertainties among composition, heating, and dilution measurements. The volatility distributions obtained from composition analysis will contain systematic errors from sensitivity and saturation concentration parameterizations. In addition, composition analysis may lose information for products with low sensitivities, although positive-mode ESI analysis can detect major known products. The results of heating measurements involve interference from thermal decomposition and the uncertainties from the parameterizations for the enthalpies of vaporization. The volatility distribution obtained from dilution measurements also include large uncertainties under high DR conditions, as discussed in the previous paragraph. Despite the probable uncertainties in composition, heating, and dilution measurements, the present results of all three methods suggest that TMB photooxidation products include low-volatility compounds with $\log _{10} C^{*}<0$, which are not predicted from yield curve analysis. Possible reasons for underestimations of low-volatility compounds by yield curve analysis are the effects of semivolatile vapor wall loss generally enhanced in batch experiments in a low-concentration region or constant product yields assumed in a gas-particle partitioning model function. In the standard VBS approach, the product volatility distributions determined by yield curve analysis are employed (e.g., Robinson et al., 2007; Lane et al., 2008). Currently, a limited number of non-standard treatments are available only for $\alpha$ pinene SOA; e.g., Trump and Donahue (2014) took into account dimer formation in the particle phase, and Yli-Juuti et al. (2017) employed the product volatility distribution determined from dilution data. Further improvement in the atmospheric organic aerosol model will be necessary not only for the study of biogenic SOA but also for anthropogenic SOA.

\section{Conclusions}

In this study, we investigated the volatility of SOA formed from TMB photooxidation by composition, heating, and dilution measurements. To our knowledge, this is the first study to determine the volatility distributions from composition and dilution measurements of SOA formed from the photooxidation of aromatic hydrocarbons. Results of the present composition study showed that $\mathrm{C}_{9} \mathrm{H}_{14} \mathrm{O}_{x}$ monomers $(x=4$ 
7) and $\mathrm{C}_{18} \mathrm{H}_{26} \mathrm{O}_{x}$ dimers $(x=8-12)$ are major products in SOA particles. These results are consistently explained by previously proposed mechanisms in which highly oxygenated $\mathrm{RO}_{2}$ radicals are generated by auto-oxidation mechanisms, and monomer and dimer products are formed by the $\mathrm{RO}_{2}+\mathrm{HO}_{2}$ and $\mathrm{RO}_{2}+\mathrm{RO}_{2}$ reactions, respectively. Dimer formation processes from particle-phase reactions or gasphase reactions of Criegee intermediates cannot be excluded because the rate constants for the $\mathrm{RO}_{2}+\mathrm{RO}_{2} \rightarrow \mathrm{ROOR}+\mathrm{O}_{2}$ reactions in the gas phase are lower than those for the $\mathrm{RO}_{2}+$ $\mathrm{HO}_{2} \rightarrow \mathrm{ROOH}+\mathrm{O}_{2}$ reactions. Monomer products with five or more oxygens were newly formed, and dimer products degraded during photochemical aging. Monomer products with five or more oxygens may be produced from the photooxidation of phenol-type gaseous products during photochemical aging, and dimer products in the particle phase may undergo photolysis during photochemical aging.

The present results of composition, heating, and dilution measurements suggest that TMB photooxidation products include compounds with volatilities less than those predicted from conventional SOA yield curve analysis. In the standard VBS approach, the product volatility distributions are determined by SOA yield curve analysis, and the distributions employed in the standard VBS approach do not include lowvolatility products. A limited number of non-standard treatments, accounting for the formation of low-volatility products, are available, but non-standard treatments are examined only for $\alpha$-pinene ozonolysis. Further improvement of the atmospheric simulation model will be necessary not only for the study of biogenic SOA formation but also for anthropogenic SOA formation. Furthermore, the volatility distribution of SOA was only studied under dry conditions in the present study. Further studies would be necessary to understand the effects of relative humidity on SOA volatility.

Data availability. All data used in this work can be found on the Figshare database (https://doi.org/10.6084/m9.figshare.10026131; Sato et al., 2019).

Supplement. The supplement related to this article is available online at: https://doi.org/10.5194/acp-19-14901-2019-supplement.

Author contributions. KS and TI designed and performed chamber experiments, TD-AMS measurements, and LC-TOF-MS analysis. YF, AF, and YK designed and carried out dilution measurements. SI and HT designed and carried out PTR-MS measurements. YM, $\mathrm{KT}$, and SS contributed to data interpretations from the viewpoint of atmospheric modeling. TH, AS, and AT gave technical support for TD-AMS measurements and also contributed to data interpretations.
Competing interests. The authors declare that they have no conflict of interest.

Acknowledgements. The authors would like to thank Akio Togashi of Randstad, Yutaka Sugaya of NIES, and Tsuyoshi Fujii of HORIBA Techno Service for their technical supports to dilution measurements. Kei Sato thanks Shinichi Enami for a useful discussion on the formation mechanisms of dimers and Yoshikatsu Takazawa for technical support in LC-TOF-MS analysis.

Financial support. This research has been supported by the Environmental Research and Technology Development Fund (grant no. 5-1408), JSPS KAKENHI (grant nos. JP25340021, JP16H06305, and JP17H01866), the Steel Foundation for Environmental Protection Technology (grant no. 14-15 Taiki-221), and the Sumitomo Foundation (grant no. 123449).

Review statement. This paper was edited by Neil M. Donahue and reviewed by three anonymous referees.

\section{References}

Aiken, A. C., DeCarlo, P. F., Kroll, J. H., Worsnop, D. R., Huffman, J. A., Docherty, K. S., Ulbrich, I. M., Mohr, C., Kimmel, J. R., Sueper, D., Sun, Y., Zhang, Q., Trimborn, A., Northway, M., Ziemann, P. J., Canagaratna, M. R., Onasch, T. B., Alfarra, M. R., Prevot, A. S. H., Dommen, J., Duplissy, J., Metzger, A., Baltensperger, U., and Jimenez, J. L.: $\mathrm{O} / \mathrm{C}$ and $\mathrm{OM} / \mathrm{OC}$ ratios of primary, secondary, and ambient organic aerosols with high-resolution time-of-flight aerosol mass spectrometry, Environ. Sci. Technol., 42, 4478-4485, https://doi.org/10.1021/es703009q, 2008.

Akimoto, H., Hoshino, M., Inoue, G., Sakamaki, F., Washida, N., and Okuda, M.: Design and characterization of the evacuable and bankable photochemical smog chamber, Environ. Sci. Technol., 13, 471-475, https://doi.org/10.1021/es60152a014, 1979.

Alfarra, M. R., Paulsen, D., Gysel, M., Garforth, A. A., Dommen, J., Prévôt, A. S. H., Worsnop, D. R., Baltensperger, U., and Coe, H.: A mass spectrometric study of secondary organic aerosols formed from the photooxidation of anthropogenic and biogenic precursors in a reaction chamber, Atmos. Chem. Phys., 6, 52795293, https://doi.org/10.5194/acp-6-5279-2006, 2006.

Atkinson, R., Baulch, D. L., Cox, R. A., Hampson Jr., R. F., Kerr, J. A., and Troe, J.: Evaluated kinetic and photochemical data for atmospheric chemistry: supplement III. IUPAC subcommittee on gas kinetic data evaluation for atmospheric chemistry, J. Phys. Chem. Ref. Data, 18, 881-1097, https://doi.org/10.1063/1.555832, 1989.

Baltensperger, U., Kalberer, M., Dommen, J., Paulsen, D., Alfarra, M. R., Coe, H., Fisseha, R., Gascho, A., Gysel, M., Nyeki, S., Sax, M., Seinbacher, M., Prevot, A. S. H., Sjögren, S., Weingartner, E., and Zenobi, R.: Secondary organic aerosols from anthropogenic and biogenic precursors, Faraday Discuss., 130, 265278, https://doi.org/10.1039/B417367H, 2005. 
DeMore, W. B., Sander, S. P., Golden, D. M., Hampson, R. F., Kurylo, M. J., Howard, C. J., Ravishankara, A. R., Kolb, C. E., and Molina, M. J.: Chemical Kinetics and Photochemical Data for Use in Stratospheric Modeling Evaluation No. 12, JPL Publication 97-4, Jet Propulsion Laboratory, California Institute of Technology, Pasadena, CA, USA, 274 pp., 1997.

Docherty, K. S., Corse, E. W., Jaoui, M., Offenberg, J. H., Kleindienst, T. E., Krug, J. D., Riedel, T. P., and Lewandowski, M.: Trends in the oxidation and relative volatility of chambergenerated secondary organic aerosol, Aerosol Sci. Tech., 52, 992-1004, https://doi.org/10.1080/02786826.2018.1500014, 2018.

Dockery, D. W., Pope III, A., Xu, X., Spengler, J. D., Ware, J. H., Fay, M. E., Ferris Jr., B. G., and Speizer, F. E.: An association between air pollution and mortality in six U.S. cities, N. Engl. J. Med., 329, 1753-1759, https://doi.org/10.1056/NEJM199312093292401, 1993.

Faulhaber, A. E., Thomas, B. M., Jimenez, J. L., Jayne, J. T., Worsnop, D. R., and Ziemann, P. J.: Characterization of a thermodenuder-particle beam mass spectrometer system for the study of organic aerosol volatility and composition, Atmos. Meas. Tech., 2, 15-31, https://doi.org/10.5194/amt-2-15-2009, 2009.

Fisseha, R., Dommen, J., Sax, M., Paulsen, D., Kalberer, M., Maurer, R., Höfler, F., Weingartner, E., and Baltensperger, U.: Identification of organic acids in secondary organic aerosol and the corresponding gas phase from chamber experiments, Anal. Chem., 76, 6535-6540, https://doi.org/10.1021/ac048975f, 2004.

Fujitani, Y., Saitoh, K., Fushimi, A., Takahashi, K., Hasegawa, S., Tanabe, K., Kobayashi, S., Furuyama, A., Hirano, S., and Takami, A.: Effect of isothermal dilution on emission factors of organic carbon and n-alkanes in the particle and gas phases of diesel exhaust, Atmos. Environ., 59, 389-397, https://doi.org/10.1016/j.atmosenv.2012.06.010, 2012.

Grieshop, A. P., Donahue, N. M., and Robinson, A. L.: Is the gas-particle partitioning in alpha-pinene secondary organic aerosol reversible?, Geophys. Res. Lett., 34, L14810, https://doi.org/10.1029/2007GL029987, 2007.

Hayes, P. L., Carlton, A. G., Baker, K. R., Ahmadov, R., Washenfelder, R. A., Alvarez, S., Rappenglück, B., Gilman, J. B., Kuster, W. C., de Gouw, J. A., Zotter, P., Prévôt, A. S. H., Szidat, S., Kleindienst, T. E., Offenberg, J. H., Ma, P. K., and Jimenez, J. L.: Modeling the formation and aging of secondary organic aerosols in Los Angeles during CalNex 2010, Atmos. Chem. Phys., 15, 5773-5801, https://doi.org/10.5194/acp-15-5773-2015, 2015.

Heinritzi, M., Simon, M., Steiner, G., Wagner, A. C., Kürten, A., Hansel, A., and Curtius, J.: Characterization of the massdependent transmission efficiency of a CIMS, Atmos. Meas. Tech., 9, 1449-1460, https://doi.org/10.5194/amt-9-1449-2016, 2016.

Hilal, S. H., Karickhoff, S. W., and Carreira, L. A.: Prediction of the vapor pressure, boiling point, heat of vaporization and diffusion coefficient of organic compounds, QSAR Comb. Sci., 22, 565574, https://doi.org/10.1002/qsar.200330812, 2003.

Huffman, J. A., Ziemann, P. J., Jayne, J. T., Worsnop, D. R., and Jimenez, J. L.: Development and characterization of a fast-stepping/scanning thermodenuder for chemically-resolved aerosol volatility measurements, Aerosol Sci. Tech., 42, 395407, https://doi.org/10.1080/02786820802104981, 2008.
Inomata, S., Sato, K., Hirokawa, J., Sakamoto, Y., Tanimoto, H., Okumura, M., Tohno, S., and Imamura, T.: Analysis of secondary organic aerosols from ozonolysis of isoprene by proton transfer reaction mass spectrometry, Atmos. Environ., 97, 397-405, https://doi.org/10.1016/j.atmosenv.2014.03.045, 2014.

IPCC: Climate Change 2013: The Physical Science Basis. Contribution of Working Group I to the Fifth Assessment Report of the Intergovernmental Panel on Climate Change, edited by: Stocker, T. F., Qin, D., Plattner, G.-K., Tignor, M., Allen, S. K., Boschung, J., Nauels, A., Xia, Y., Bex, V., and Midgley, P. M., Cambridge University Press, Cambridge, UK and New York, NY, USA, 1535 pp., 2013.

Izumi, K. and Fukuyama, T.: Photochemical aerosol formation from aromatic hydrocarbons in the presence of $\mathrm{NO}_{x}$, Atmos. Environ. A-Gen., 24, 1433-1441, https://doi.org/10.1016/09601686(90)90052-O, 1990 .

Jenkin, M. E., Saunders, S. M., Wagner, V., and Pilling, M. J.: Protocol for the development of the Master Chemical Mechanism, MCM v3 (Part B): tropospheric degradation of aromatic volatile organic compounds, Atmos. Chem. Phys., 3, 181-193, https://doi.org/10.5194/acp-3-181-2003, 2003.

Kalberer, M., Paulsen, D., Sax, M., Steinbacher, M., Dommen, J., Prevot, A. S. H., Fisseha, R., Weingartner, E., Frankevich, V., Zenobi, R., and Baltensperger, U.: Identification of polymers as major components of atmospheric organic aerosols, Science, 303, 1659-1662, https://doi.org/10.1126/science.1092185, 2004.

Kamens, R. M., Zhang, H., Chen, E. H., Zhou, Y., Parikh, H. M., Wilson, R. L., Galloway, K. E., and Rosen, E. P.: Secondary organic aerosol formation from toluene in an atmospheric hydrocarbon mixture: Water and particle seed effects, Atmos. Environ., 45, 2324-2334, https://doi.org/10.1016/j.atmosenv.2010.11.007, 2011.

Kelly, J. M., Doherty, R. M., O’Connor, F. M., and Mann, G. W.: The impact of biogenic, anthropogenic, and biomass burning volatile organic compound emissions on regional and seasonal variations in secondary organic aerosol, Atmos. Chem. Phys., 18, 7393-7422, https://doi.org/10.5194/acp-18-7393-2018, 2018.

Kolesar, K. R., Li, Z., Wilson, K. R., and Cappa, C. D.: Heating-induced evaporation of nine different secondary organic aerosol types, Environ. Sci. Technol., 49, 12242-12252, https://doi.org/10.1021/acs.est.5b03038, 2015.

Kruve, A., Kaupmees, K., Liigand, J., Oss, M., and Leito, I.: Sodium adduct formation efficiency in ESI source, J. Mass Spectrom., 48, 695-702, https://doi.org/10.1002/jms.3218, 2013.

Lane, T. E., Donahue, N. M., and Pandis, S. N.: Simulating secondary organic aerosol formation using the volatility basisset approach in a chemical transport model, Atmos. Environ., 42, 7439-7451, https://doi.org/10.1016/j.atmosenv.2008.06.026, 2008.

Li, Y., Pöschl, U., and Shiraiwa, M.: Molecular corridors and parameterizations of volatility in the chemical evolution of organic aerosols, Atmos. Chem. Phys., 16, 3327-3344, https://doi.org/10.5194/acp-16-3327-2016, 2016.

Lindinger, W., Hansel, A., and Jordan, A.: Proton-transfer-reaction mass spectrometry (PTR-MS): on-line monitoring of volatile organic compounds at pptv levels, Chem. Soc. Rev., 27, 347-354, https://doi.org/10.1016/S0168-1176(97)00281-4, 1998.

Molteni, U., Bianchi, F., Klein, F., El Haddad, I., Frege, C., Rossi, M. J., Dommen, J., and Baltensperger, U.: Formation of highly 
oxygenated organic molecules from aromatic compounds, Atmos. Chem. Phys., 18, 1909-1921, https://doi.org/10.5194/acp18-1909-2018, 2018.

Morino, Y., Nagashima, T., Sugata, S., Sato, K., Tanabe, K., Noguchi, T., Takami, A., Tanimoto, H., and Ohara, T.: Verification of chemical transport models for $\mathrm{PM}_{2.5}$ chemical composition using simultaneous measurement data over Japan, Aerosol Air Qual. Res., 15, 2009-2023, https://doi.org/10.4209/aaqr.2015.02.0120, 2015.

Nakao, S., Clark, C., Tang, P., Sato, K., and Cocker III, D.: Secondary organic aerosol formation from phenolic compounds in the absence of NOx, Atmos. Chem. Phys., 11, 10649-10660, https://doi.org/10.5194/acp-11-10649-2011, 2011.

Ng, N. L., Kroll, J. H., Chan, A. W. H., Chhabra, P. S., Flagan, R. C., and Seinfeld, J. H.: Secondary organic aerosol formation from m-xylene, toluene, and benzene, Atmos. Chem. Phys., 7, 3909-3922, https://doi.org/10.5194/acp-7-3909-2007, 2007.

Odum, J. R., Jungkamp, T. P. W., Griffin, R. J., Flagan, R. C., and Seinfeld, J. H.: The atmospheric aerosol-forming potential of whole gasoline vapor, Science, 276, 96-99, https://doi.org/10.1126/science.276.5309.96, 1997.

Praplan, A. P., Hegyi-Gaeggeler, K., Barmet, P., Pfaffenberger, L., Dommen, J., and Baltensperger, U.: Online measurements of water-soluble organic acids in the gas and aerosol phase from the photooxidation of 1,3,5-trimethylbenzene, Atmos. Chem. Phys., 14, 8665-8677, https://doi.org/10.5194/acp-148665-2014, 2014.

Praske, E., Otkjær, R. V., Crounse, J. D., Hethcox, J. C., Stoltz, B. M., Kjaergaard, H. G., and Wennberg, P. O.: Atmospheric autoxidation is increasingly important in urban and suburban North America, P. Natl. Acad. Sci. USA, 115, 64-69, https://doi.org/10.1073/pnas.1715540115, 2018.

Robinson, A. L., Donahue, N. M., Shrivvastava, M. K., Weitkamp, E. A., Sage, A. M., Grieshop, A. P., Lane, T. E., Pierce, J. R., and Pandis, S. N.: Rethinking organic aerosols: Semivolatile emissions and photochemical aging, Science, 315, 1259-1262, https://doi.org/10.1126/science.1133061, 2007.

Saleh, R., Donahue, N. M., and Robinson, A. L.: Time scales for gas-particle partitioning equilibration of secondary organic aerosol formed from alpha-pinene ozonolysis, Environ. Sci. Technol., 47, 5588-5594, https://doi.org/10.1021/es400078d, 2013.

Sato, K., Klotz, B., Hatakeyama, S., Imamura, T., Washizu, Y., Matsumi, Y., and Washida, N.: Secondary organic aerosol formation during the photo-oxidation of toluene: dependence on initial hydrocarbon concentration, B. Chem. Soc. Jpn., 77, 667-671, https://doi.org/10.1246/bcsj.77.667, 2004.

Sato, K., Hatakeyama, S., and Imamura, T.: Secondary organic aerosol formation during the photooxidation of toluene: $\mathrm{NO}_{x}$ dependence of chemical composition, J. Phys. Chem. A, 111, 9796-9808, https://doi.org/10.1021/jp071419f, 2007.

Sato, K., Takami, A., Kato, Y., Seta, T., Fujitani, Y., Hikida, T., Shimono, A., and Imamura, T.: AMS and LC/MS analyses of SOA from the photooxidation of benzene and 1,3,5trimethylbenzene in the presence of $\mathrm{NO}_{x}$ : effects of chemical structure on SOA aging, Atmos. Chem. Phys., 12, 4667-4682, https://doi.org/10.5194/acp-12-4667-2012, 2012.

Sato, K., Fujitani, Y., Inomata, S., Morino, Y., Tanabe, K., Ramasamy, S., Hikida, T., Shimono, A., Takami, A., Fushimi,
A., Kondo, Y., Imamura, T., Tanimoto, H., and Sugata, S.: Studying volatility from composition, dilution, and heating measurements of secondary organic aerosols formed during $\alpha$-pinene ozonolysis, Atmos. Chem. Phys., 18, 5455-5466, https://doi.org/10.5194/acp-18-5455-2018, 2018.

Sato, K., Fujitani, Y., Inomata, S., Morino, Y., Tanabe, K., Hikida, T., Shimono, A., Takami, A., Fushimi, A., Kondo, Y., Imamura, T., Tanimoto, H., and Sugata, S.: Data for "A study of volatility by composition, heating and dilution measurements of secondary organic aerosol from 1,3,5-trimethylbenzene", FigShare, https://doi.org/10.6084/m9.figshare.10026131, 2019.

Shiraiwa, M., Berkemeier, T., Schilling-Fahnestock, K. A., Seinfeld, J. H., and Pöschl, U.: Molecular corridors and kinetic regimes in the multiphase chemical evolution of secondary organic aerosol, Atmos. Chem. Phys., 14, 8323-8341, https://doi.org/10.5194/acp-14-8323-2014, 2014.

Shiraiwa, M., Ueda, K., Pozzer, A., Lammel, G., Kampf, C. J., Fushimi, A., Enami, S., Arangio, A. M., Fröhlich-Nowoisky, J., Fujitani, Y., Furuyama, A., Lakey, P. S. J., Lelieveld, J., Lucas, K., Morino, Y., Poschl, U., Takahama, S., Takami, A., Tong, H., Weber, B., Yoshino, A., and Sato, K.: Aerosol health effects from molecular to global scales, Environ. Sci. Technol., 51, 1354513567, https://doi.org/10.1021/acs.est.7b04417, 2017.

Smith, D. F., Kleindienst, T. E., and McIver, C. D.: Primary product distributions from the reaction of $\mathrm{OH}$ with $\mathrm{m}$-, p-xylene, 1,2,4-and 1,3,5-trimethylbenzene, J. Atmos. Chem., 34, 339364, https://doi.org/10.1023/A:1006277328628, 1999.

Trump, E. R. and Donahue, N. M.: Oligomer formation within secondary organic aerosols: equilibrium and dynamic considerations, Atmos. Chem. Phys., 14, 3691-3701, https://doi.org/10.5194/acp-14-3691-2014, 2014.

Wang, S., Wu, R., Berndt, T., Ehn, M., and Wang, L.: Formation of highly oxidized radicals and multifunctional products from the atmospheric oxidation of alkylbenzenes, Environ. Sci. Technol., 51, 8442-8449, https://doi.org/10.1021/acs.est.7b02374, 2017.

Wu, R. and Xie, S.: Spatial distribution of secondary organic aerosol formation potential in China derived from speciated anthropogenic volatile organic compound emissions, Environ. Sci. Technol., 52, 8146-8156, https://doi.org/10.1021/acs.est.8b01269, 2018.

Yli-Juuti, T., Pajunoja, A., Tikkanen, O.-P., Buchholz, A., Faiola, C., Väisänen, O., Hao, L., Kari, E., Peräkylä, O., Garmash, O., Shiraiwa, M., Ehn, M., Lehtinen, K., and Virtanen, A.: Factors controlling the evaporation of secondary organic aerosol from $\alpha$-pinene ozonolysis, Geophys. Res. Lett., 44, 2562-2570, https://doi.org/10.1002/2016GL072364, 2017.

Zhang, Q., Jimenez, J. L., Canagaratna, M. R., Allan, J. D., Coe, H., Ulbrich, I., Alfarra, M. R., Takami, A., Middlebrook, A. M., Sun, Y. L., Dzepina, K., Dunlea, E., Docherty, K., DeCarlo, P. F., Salcedo, D., Onasch, T., Jayne, J. T., Miyoshi, T., Shimono, A., Hatakeyama, S., Takegawa, N., Kondo, Y., Schneider, J., Drewnick, F., Borrmann, S., Weimer, S., Demerjian, K., Williams, P., Bower, K., Bahreini, R., Cottrell, L., Griffin, R. J., Rautiainen, J., Sun, J. Y., Zhang, Y. M., and Worsnop, D. R.: Ubiquity and dominance of oxygenated species in organic aerosols in anthropogenically-influenced Northern Hemisphere midlatitudes, Geophys. Res. Lett., 34, L13801, https://doi.org/10.1029/2007GL029979, 2007. 
Zhang, X., Lambe, A. T., Upshur, M. A., Brooks, W., Gray Bé, A., Thomson, R. J., Geiger, F. M., Surratt, J. D., Zhang, Z., Gold, A., Graf, S., Cubison, M. J., Groessl, M., Jayne, J. T., Worsnop, D. R., and Canagaratna, M. R.: Highly oxygenated multifunctional compounds in $\alpha$-pinene secondary organic aerosol, Environ. Sci. Technol., 51, 5932-5940, https://doi.org/10.1021/acs.est.6b06588, 2017.
Zhou, Y., Zhang, H., Parikh, H. M., Chen, E. H., Rattanavaraha, W., Rosen, E. P., Wang, W., and Kamens, R. M.: Secondary organic aerosol formation from xylenes and mixtures of toluene and xylenes in an atmospheric urban hydrocarbon mixture: Water and particle seed effects (II), Atmos. Environ., 45, 3882-3890, https://doi.org/10.1016/j.atmosenv.2010.12.048, 2011. 